\title{
Study on the Effect of Niche Market Opportunities on Internationalization Degree and International Performance
}

\author{
Zhongwei $\mathrm{CaO}^{1, \mathrm{a}^{*}}$ Jiang $\mathrm{Xu}^{2, \mathrm{~b}}$ and Yueli $\mathrm{Liu}^{3, \mathrm{c}}$ \\ ${ }^{1}$ Department of Applied Mathematics, Jilin University of Finance and Economics, Changchun \\ 130117, P.R.China \\ ${ }^{2}$ School of Econimics and Management, Changchun University of Technology, Changchun 130000, \\ P.R.China \\ ${ }^{3}$ Department of Finance, Jilin University of Finance and Economics, Changchun 130117, P.R.China \\ a Caozw963@sina.com, bxujiang_1976@163.com, ' 2425827438@qq.com \\ * The corresponding author
}

Keywords: Niche market opportunity; Degree of internationalization; International performance

\begin{abstract}
The literature of internationalization discusses the internationalization of small and medium-sized enterprises mainly from two perspectives: the internationalization stage theory and the recent phenomenon of "natural globalization". In the world economy and trade, although the importance of small and medium enterprises is self-evident, there is little research and analysis of the importance of niche market for small and medium-sized enterprises. Based on this, this paper studies the effect of niche market opportunities on internationalization degree and international performance. The results show that the niche market opportunities faced by SMEs are positively related to the international performance of enterprises and the degree of internationalization of enterprises. Finally, this paper puts forward the corresponding enlightenment.
\end{abstract}

\section{Introduction}

In the field of strategic management, market opportunities determine the survival and development of enterprises to a certain extent. According to Webber's book in the book of "Discrimination of Market Practices", the popular marketing model used in the past has become outdated. Companies must know how to adapt to local conditions and achieve success. Popularization has become a concept. Only by defining a clear market differentiation can we clearly understand the needs of the target market. The niche market is the region of this kind of market. For small and medium-sized enterprises, looking for market opportunities, "drilling market holes", providing products or services for consumers seeking special interests, and obtaining market niche, will be the key to the rapid gain of competitive advantage for small and medium-sized enterprises. In this niche market, enterprises have fewer competitors in the market, and according to the principle of "enterprise $80 \%$ 's profit from $20 \%$ products", SMEs will actively seek overseas niche markets and explore niche market opportunities because of their weak products and competitiveness. As Chandler et al. (2011) [1] said in its book "long tail theory", for small and medium-sized enterprises, because the domestic competition is becoming more and more hot, these enterprises cannot simply expect to earn most of the benefit from the small part of the best seller. In the international market, the unpopular goods and small customers are the niche market opportunities, multiple unpopular goods are gathered together, and the multiple niche markets opportunities are opened up, then the small and medium enterprises will get a huge market. When SMEs can identify overseas niche market opportunities, their "opportunities really come" (Crossan, 1998) [2]. But so far, most studies have studied the essence of the niche market in the internationalization process through the long tail theory niche market opportunity identification and utilization. Few studies have integrated niche market opportunities with the internationalization of SMEs and international performance to research. Therefore, from the perspective of market opportunities, this paper will explore the impact of niche market opportunities on the internationalization of SMEs. 


\section{Related Concepts}

Niche Market Opportunities. The niche market is separated by the market. It is a smaller market, which is made up of consumers seeking some special interests and has fewer competitors in the market. The traditional business management tells us that the profit of $80 \%$ of the enterprise comes from $20 \%$ products, and every enterprise will seek for the star products, and then cultivate it. However, as the market contends, there are more and more commodities. Crossan et al. (2005) [3]mentioned in his book "The Long Tail Theory" that companies can no longer expect to earn most of their profits from a small portion of best-selling products. Multiple unpopular goods are gathered together, and the multiple niche markets opportunities are opened up, then the small and medium enterprises will get a huge market that is much larger than the best-selling goods. The long-tailed market is extremely large in scale, adding up the market size of unpopular goods and even competing with best-selling products.

Based on the above analysis, this paper defines the niche market opportunity as: compared with the traditional market, it is the market that is subdivided into multiple subsegments, and then the company explores the market opportunities which and can be exploited and bring potential benefits to the company in different market segments.

International Performance. Deligianni et al. (2017) [4] defines the performance of internationalization. He believes that international performance is the output of an enterprise in the process of international operation. It contains three parts, the first is the productivity and production efficiency of International, which is mainly reflected in the promotion of international capacity, and the second is the international output performance. That is, financial performance, such as international sales growth rate, international profit and so on. The last is non-financial indicators, mainly the satisfaction and recognition of foreign customers and the satisfaction of international employees. Internationalization performance is the final result of resource input in the process of internationalization of enterprises, and it is the result of transnational allocation of resources. To sum up, this paper holds that international performance refers to the output produced by the resource input in the process of international operation, which is basically manifested in the financial performance of the enterprise. It is the basic indicator of the success of the enterprise internationalization.

Internationalization Degree. Miner et al. (2001) [5]summarizes the measure of internationalization used by scholars in the past, classified as performance attribute, structure attribute and attitude attribute. The performance attributes include: the proportion of overseas sales to total sales, the intensity of $\mathrm{R}$ \&amp; D expenditure, the density of advertising expenditure, the proportion of export sales to total sales, and the proportion of overseas profits to total profits. Institutional attributes include the ratio of overseas assets to total assets and the proportion of overseas subsidiaries to total subsidiaries. Attitude attributes include: international experience of top management and psychological decentralization of international operation. The former two are objective performance, while the latter are subjective performance, the results are very close.

\section{Analysis of the Influence Mechanism}

Because of the small-scale fact, the niche market, which has significant growth potential but low demand and often neglected by large companies, is the usual choice for SMEs. Small and medium-sized enterprises are very concerned and sensitive to capture the increasing number of niche markets that have emerged as the degree of specialization in the market is increasing, and they can efficiently use its resources to provide quality products and services to the market.

SMEs not only have a sensitive international response, but also have a strong sense of international market positioning. These companies are closely concerned with the changes in the needs of overseas consumers and adapt to the change through product adjustment. Enterprises also establish and maintain a stable relationship with consumers through close attention to consumer behavior. 
Moorman and Miner (1998) [6]believes that, after entering the selected niche market, small and medium enterprises will make use of market opportunities to adjust the niche strategy of the enterprises. Small and medium-sized enterprises should adhere to the specialization orientation and make customized production according to the needs of the customers. Because the niche market has the characteristics of simple market scope, in such a market, the limited resources of small and medium-sized enterprises are more effective, the utilization efficiency of resources will be improved, and the performance of internationalization will benefit from the effective utilization of resources. The value activities and core technologies concentrated in certain niche markets are relatively simple for small and medium-sized enterprises, which is more likely to have unique advantages for small and medium sized enterprises with relatively less resources. This advantage is the opportunity brought by niche market in the process of internationalization of SMEs, which is conducive to the improvement of their international performance. The niche market sought by small and medium enterprises, as a result of the single purification of business scope, makes the enterprise have the opportunity to improve efficiency in various processes, and the improvement of the process will improve performance. At this time, the scale becomes unimportant, instead of optimizing the process by optimizing the resources and improving the efficiency of the process while improving the efficiency of the process. This is the key to improving the performance of small and medium-sized enterprises with limited resources.

Small and medium enterprises are constantly looking for niche opportunities, but in a rapidly changing market environment, small and medium-sized enterprises must constantly interpret and understand the opportunities brought about by the foreign niche markets. By allocating resources and processes, using the professional skills of enterprises, make the niche market opportunities to be the basis of international operation, and then we can create more benefits. Therefore, the niche market opportunities faced by SMEs are positively related to the internationalization performance of enterprises.

For small and medium-sized enterprises, the opportunity to seek niche markets contains three major contents, the first is the identification of existing opportunities, the second is the development of potential opportunities, and the third is the creation of new opportunities. Three different types for seeking all have a significant impact on the internationalization of SMEs. The Taiwan scholars analyse the characteristics of the niche market opportunities. They believes that the niche market opportunities reflect the narrow product market and the broad regional market, and the opportunity for small and medium-sized enterprises is also potential. If a small and medium-sized enterprise specializes in specific products, when a niche market has the unique and identical customer form and consumption pattern, the small and medium sized enterprises can take their special products into specific niche markets to seize the opportunity. At this time, small and medium-sized enterprises must have the ability to identify this opportunity, next, the internationalization degrees will be gradually promoted according to the control of opportunities by enterprises. It is found that in order to achieve growth and sustainable management in the process of internationalization, small and medium-sized enterprises must develop the niche market opportunities. If the same products are put to the same or similar markets, the enterprises need to make a breakthrough in the process of internationalization: expanding a number of international markets or researching a variety of products. The market for the same demand is a niche market for other product, which can meet the same demand market in comparison with the original niche market of small and medium-sized enterprises. In short, it is to enter the other product areas that can meet the demand of the same market. At the same time, SMEs are not only required to pay attention to the potential niche market demand, but also to speed up their internationalization process. And when a market is not effectively developed, or a strong competitor ignores the development of one aspect, small and medium enterprises can create niche opportunities by providing quality products and services. In other words, by meeting the differences between the means and methods of the competitors to meet the needs of consumers in the field and the highest satisfaction of consumers, the demand of consumers is well satisfied, which is the niche market opportunity created by small and medium-sized enterprises. This requires small and medium-sized enterprises to test the situation, 
not only to test the market at any time or to understand the demand of the market, but also to speed up the internationalization process in the process of internationalization, and improve the level and level of internationalization. Therefore, niche opportunities faced by SMEs are positively related to the degree of internationalization of enterprises.

\section{Research Inspiration}

If SMEs can grasp the opportunities provided by niche market, they can easily enhance their international performance. When there is a "gap" in an overseas market, or one aspect is "seen" by other competitors, when small and medium-sized enterprises are good at making up the demand of this gap market, the enterprise will seize the opportunity of profit. Only by grasping the opportunity of niche market, being good at "filling in", avoiding the traditional market and avoiding the direct competition with large enterprises, small and medium enterprises can seize the potential and valuable opportunities in the niche market, and then improve the international performance quickly. For small and medium-sized enterprises, if the enterprise has a deep insight and the market scanning abilities, it can always see the existence of overseas opportunities, and in such an overseas market, there are fewer competitors, and small and medium-sized enterprises can seize the opportunity to improve their performance as long as they are able to make a timely strategy. This is also the key for some SMEs to take the first step in internationalization. In the same way, small and medium-sized enterprises find and seize the opportunities that are smaller in the market and are not "favored" by large enterprises and can also bring good performance to small and medium-sized enterprises.

For small and medium sized enterprises, niche market is an opportunity for the development of small and medium enterprises. Taking advantage of niche market opportunities and exploiting niche markets can promote small and medium-sized enterprises to choose a specific product or service field, and focus on taking advantage of this opportunity and becoming a leader. We know that in the Chinese market, for small and medium-sized enterprises, resources are very limited. In the face of fierce competition in the market globalization, Chinese small and medium-sized enterprises have a large gap in human, material, financial, technical, production, marketing, brand, management and other marketing resources. Many small and medium-sized enterprises have just come out of the country and do not have enough resources and strong competitiveness. Moreover, in the international market, the brutal competition environment forces enterprises to use resources in order to survive. Although China's enterprises are unable to compete with the multinational enterprises, they can concentrate resources in a small and narrow and diverse consumer group market in order to cope with the competitors' attack, and even become the magic weapon of the Chinese enterprises. Therefore, for small and medium-sized enterprises, the first is to carefully select a customer group, and focus on the needs of such customers; the second is to make the product unique value for attracting potential customers; and the third is to design a different path from other enterprises. Sometimes, the channel strategy of an enterprise may become the sole competitive advantage and foundation of an enterprise. But in the past enterprise competition strategy, few people raised them to a strategic position. For a small and medium-sized enterprise, for a late development enterprise, for a mature market of new products, niche channels may become a magic weapon for victory.

\section{Acknowledgement}

The authors would like to thank NSFC (No. 11701209), the Project of Science and Technology Development Plan for Jilin Province (No.20160520110JH) and Science and Technology Research Project of Jilin Provincial Department of Education of China (JJKH20180462KJ,2015162) for financially supporting this research. 


\section{References}

[1] Chandler G N, DeTienne D R, McKelvie A, et al. Causation and effectuation processes: A validation study. Journal of business venturing, 26(2011)375-390.

[2] Crossan M. Improvisation in action. Organization Science, 9(1998)593-599.

[3] Crossan M, Cunha M P E, Vera D, et al. Time and organizational improvisation. Academy of Management Review, 30(2005) 129-145.

[4] Deligianni I, Voudouris I, Lioukas S. Do effectuation processes shape the relationship between product diversification and performance in new ventures?. Entrepreneurship Theory and Practice, 41(2017)349-377.

[5] Miner A S, Bassoff P, Moorman C. Organizational Improvisation and Learning: A Field Study. Administrative Science Quarterly, 46(2001)304-337.

[6] Moorman C, Miner A S. Organizational improvisation and organizational memory. Academy of management Review, 23(1998) 698-723. 